\section{Durable Left Ventricular Assist Device with Mechanical Mitral and Aortic Valves}

Sir,

Bioprosthetic valve or repair is considered when advanced heart failure patients with severe valvular disease require a left ventricular assist device (LVAD); and those already with a mechanical aortic valve should have a replacement with a bioprosthetic valve. ${ }^{1}$ Operative mortality is high with combined surgical procedures of LVAD implantation and mechanical valve replacement. ${ }^{2}$ We report an uncommon case with followup for a patient whose mechanical aortic and mitral valves were not replaced at the time of LVAD implantation.

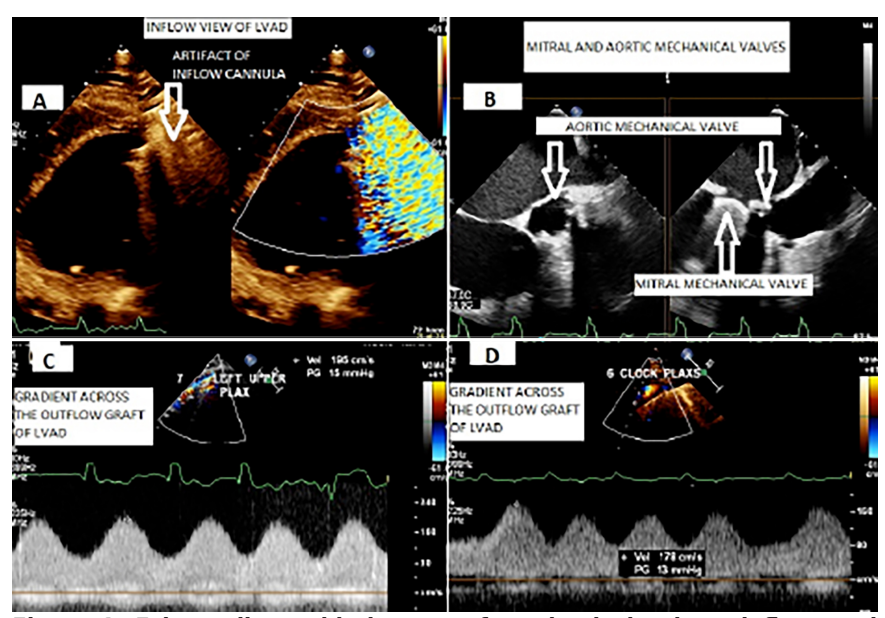

Figure 1: Echocardiographic images of mechanical valves, inflow, and outflow grafts of left ventricular assist device (LVAD). A: Inflow cannula of left ventricular assist device (LVAD). B: Mechanical mitral and aortic valves. C: Gradient across outflow graft in left upper parasternal long axis view. $D$ : Gradientacross outflow graft at 60 ' clock parasternal long axis view.

A 57-year man had aortic and mitral mechanical prosthetic valves implanted 20 years back and underwent LVAD implantation in September 2018 as a bridge to transplant. His echo showed a left ventricular ejection fraction of $10 \%$ with well seated mitral and aortic mechanical prosthetic valves without abnormally increased gradients (Figure 1B). The inflow and outflow grafts of LVAD did not show any echo features of stenosis (Figures 1A, C, D). During the follow-up of 545 days, he remained stable with NYHA class 1 and free from clinical stroke or significant bleeding. Mean arterial pressure was maintained between 70 to $80 \mathrm{mmHg}$ with bisoprolol and candesartan; and INR was maintained between 3 and 3.5 with warfarin. His auto log files showed mean power: 4.7W (4.2 - 5.5), mean flow: 4.2 LPM (3.0 - 5.7), and mean pulsatility: 3.2 LPM (1.1 - 4.6). There was no laboratory or imaging suggestion of pump or pre/post-pump thrombosis.

Guidelines suggest replacement of the mechanical aortic valve with a bioprosthetic valve at the time of LVAD implantation. ${ }^{3}$
Mechanical aortic valve with LVAD was present in seven patients with a mean duration of support for 48 days without an increase in thromboembolism or significant bleeding. ${ }^{2}$ High mortality was suggested in another study due to underlying advanced heart disease rather than a pump orvalve thrombosis or dysfunction. ${ }^{4}$ This case report, in line with the published reports, demonstrated the safety of LVAD in patients with mechanical aortic and mitral valves with no significant bleeding or clinically relevant thromboembolic event throughout the follow-up of 545 days. Anticoagulation with warfarin needs to be monitored carefully and INR should be kept around $3(2.5-3.5)$ along with the aspirin. There was no survival difference between patients with LVAD having mechanical valves or bioprosthetic valves. ${ }^{5}$ Patients with a mechanical aortic valve, having intermac $\mathrm{I} / \mathrm{II}$ and planned for LVAD as a bridge to transplant, might be considered for LVAD implantation without replacement with a bioprosthetic valve.

\section{CONFLICT OF INTEREST:}

The authors declared no conflict of interest.

\section{AUTHORS' CONTRIBUTION:}

MAS, FAG: Conception, drafting, and final approval; and agreed to be accountable for all the aspects of work.

\section{REFERENCES}

1. Teresa SW, Adrian FH, Michael F, Carmelo AM, Joseph GR, Chetan BP. Valvular heart disease in patients supported with left ventricular assist devices. Circ Heart Fail 2014; 7(1):215-22. doi: 10.1161/Circheartfailure.113.000473.

2. Fatima K, Abhishek S, Rene JA Jr. Patients with prosthetic valves and need for left ventricular assist device. J Cardiac Failure 2016; 22(8):S120. doi.org/ 10.1016/j.cardfail.2016.06.375.

3. Feldman D, Pamboukian SV, Teuteberg JJ, Birks E, Lietz K, Moore SA, et al. The 2013 international society for heart and lung transplantation guidelines for mechanical circulatory support: Executive summary. J Heart Lung Transplant 2013; 32(2): 157-187. doi: 10.1016/j.healun.2012.09.013.

4. Schweiger M1, Stepanenko A, Vierecke J, Drews T, Potapov E, Hetzer R, et al. Preexisting mitral valve prosthesis in patients undergoing left ventricular assist device implantation. Artif Organs 2012; 36(1):49-53. doi: 10.1111/j.1525-1594.2011.013 04.x.

5. Fatima K, Farhan R, Donald CH, Soundarapandian V, Rene A. outcomes in patients with mechanical and bioprosthetic valves undergoing left ventricular assist device implantation. JACC 2018; 71(11):807. 
Department of Cardiology, King Fahad Medical City, Riyadh, Saudi Arabia

Correspondence to: Dr. Muhammad Adil Soofi, Department of Cardiology, King Fahad Medical City, Riyadh, Saudi Arabia
E-mail: adilsoofi@hotmail.com

Received: October 17, 2020; Revised: March 31, 2021; Accepted: April 24, 2021

DOI: https://doi.org/10.29271/jcpsp.2021.12.1516

$\bullet \bullet \bullet \bullet \bullet \bullet \bullet \bullet \bullet$ 